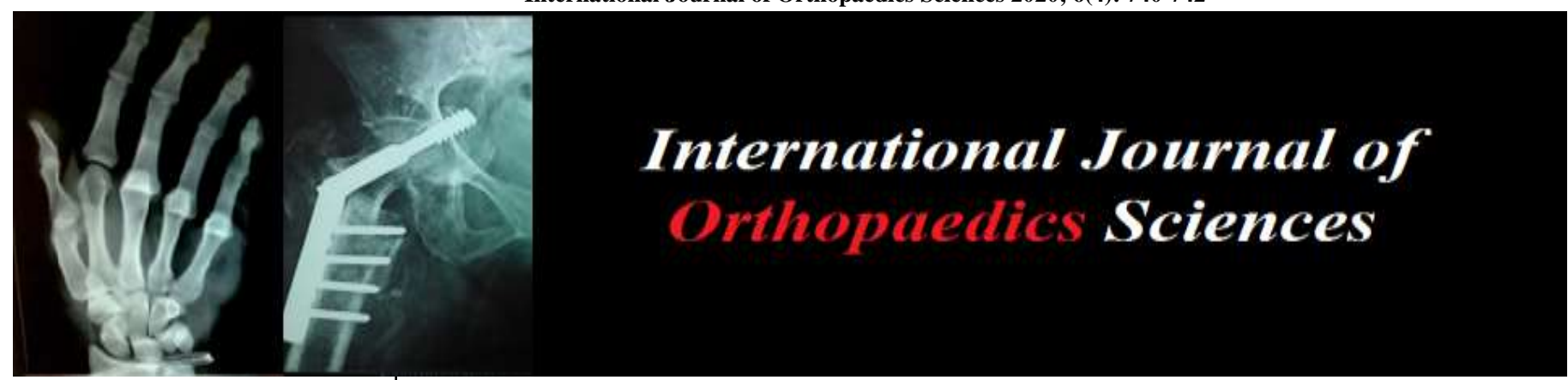

E-ISSN: 2395-1958

P-ISSN: 2706-6630

IJOS 2020; 6(4): 740-742

(C) 2020 IJOS

www.orthopaper.com

Received: 23-08-2020

Accepted: 09-10-2020

Paragjyoti Gogoi

Assistant Professor,

Department of Orthopaedics \&

Trauma, Guwahati Medical

College, Assam, India

Gautam Chandra Paul

Registrar, Department of

Orthopaedics \& Trauma, Diphu

Medical College, Assam, India

Aditi Das

Assistant Professor, Department

of Radio-Diagnosis, Silchar

Medical College, Assam, India
Corresponding Author:

Paragjyoti Gogoi

Assistant Professor,

Department of Orthopaedics \&

Trauma, Guwahati Medical

College, Assam, India

\section{Traumatic bilateral hip dislocation; one anteriorly and one posteriorly in adult: A case report and brief review of literature}

\section{Paragjyoti Gogoi, Gautam Chandra Paul and Aditi Das}

DOI: https://doi.org/10.22271/ortho.2020.v6.i4k.2412

Abstract

Bilateral asymmetric traumatic hip dislocation is a rare orthopaedic condition. Only few cases are reported in the literature. Most of the bilateral hip dislocations are posterior dislocation. In few numbers it is a combination of both anterior and posterior dislocation. We report such a case of asymmetric traumatic bilateral hip dislocation in an adult of 30 years of age. Reduced under general anaesthesia within four hours, both the hip showed concentric reduction.

Keywords: Hip dislocation, asymmetric, bilateral, adult, avascular necrosis

\section{Introduction}

Hip dislocation in adult is a major traumatic event. Because of deeper ball and socket congruency, tough ligaments around, and bulky muscle cover the hip is a stable joint in normal range of movement. Only in extremes of range like flexion, adduction and internal rotation the hip is vulnerable for dislocation posteriorly provided there is sufficient traumatic force. Anterior dislocation is less common because of more abnormal posture it requires along with the trauma i.e. abduction, extension and external rotation. Moreover the tough ilio-femoral ligament always acts as a restraint along with the capsule. Bilateral dislocations are rare event and they are mostly posterior dislocation. High velocity injuries in vulnerable positions are required to cause these. Asymmetric bilateral hip dislocations means one hip dislocates anteriorly while the other dislocates posteriorly. They are found very rarely and only a few cases are reported of such types ${ }^{[1-10]}$. In these cases one hip should be in flexed, adducted and internally rotated, while the other hip in abducted, extended and externally rotated postion during the impact. We presented a case of asymmetrical bilateral traumatic hip dislocation in adult.

\section{Case Report}

A 30 years old male person was presented to our Casualty following road traffic accident with severe pain in both hips with deformities. He reached our Casualty after 2 hours of the accident. He was conscious and his vitals were within normal limits. His head and neck area, chest, upper limbs were normal except minor abrasions. He was unable to move the hips and to sit or stand. The left hip was flexed, adducted and internally rotated while the right hip was abducted and externally rotated. The movement were grossly restricted with severe pain. The right inguinal area was full and the femoral head could be palpated. The left femoral head could be palpable at the buttock. Distal pulsation in both the lower limbs were normal. No sensory-motor deficit was noted in any of the limbs.

$\mathrm{X}$-rays of the pelvis and hips showed anterior dislocation of the right hip and posterior dislocation of left hip. However no fracture was noted. Closed reduction was tried in the ED under anaesthesia and both the hips were relocated. The time period from the accident to reduction of dislocation was around 4 hours. Post reduction $\mathrm{x}$-rays showed congruent joints. Skin traction was applied to both lower limbs and the patient was admitted. He was discharged after 3 weeks with an advice of non weight bearing for another 6 weeks. He was reviewed after 2 months and had good range of movement and no pain around the hips. 


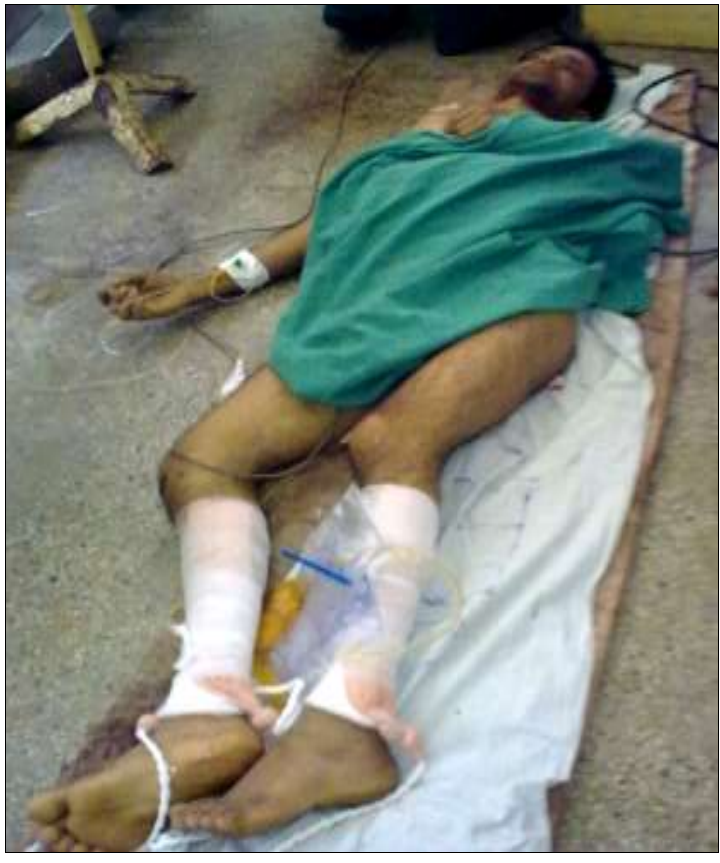

Fig 1: Clinical Photo

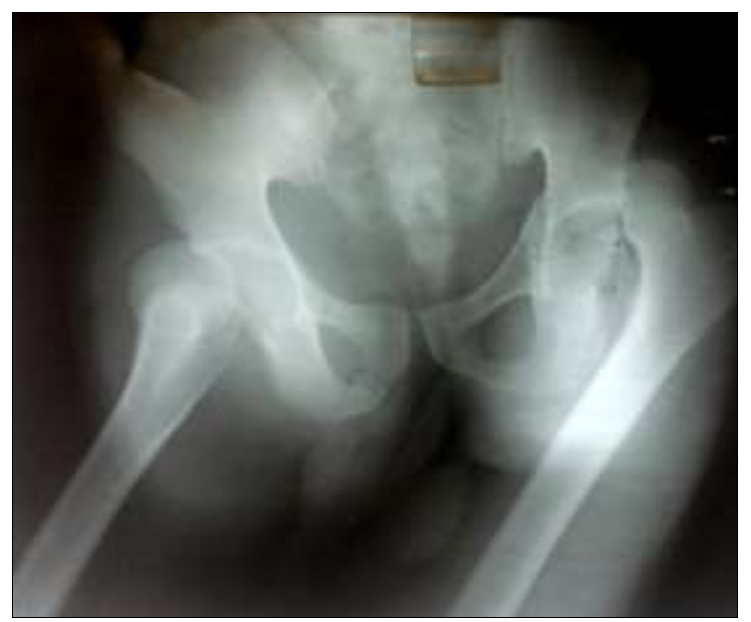

Fig 2: Pre-reduction X-ray

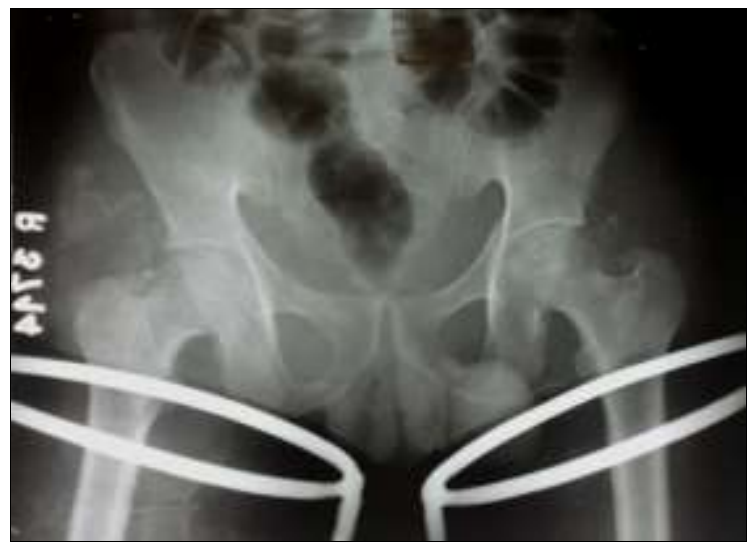

Fig 3: Post-reduction X-ray

\section{Discussion}

The incidence of hip dislocation is now rising because of increase in numbers of road traffic accidents. Most of them are posterior dislocation. About $90 \%$ of all dislocations are posterior one. Bilateral dislocations of hip are rare occurrences. Some series mention $1.25 \%$ of all dislocations are bilateral ${ }^{[1,2]}$. Bilateral asymmetric dislocations are rarer. Only a few cases are reported till date ${ }^{[3-15]}$. The precise mechanism of these dislocations is still elusive. During the time of accident one hip should be in flexed, adducted and internally rotated position while the other hip should be in abducted and externally rotated position and the trauma must be significant in both hips. This 'windswept position' with significant trauma may be a predisposing factor $\left.{ }^{[9,} 18\right]$. In Indian scenario overcrowded jeep drivers use to assume this posture. Their right side which is on the accelerator is flexed, abducted and externally rotated while the left side which is on the clutch is flexed, adducted and internally rotated because of overcrowding. Head on collision in that position may dislocate both the hips in different directions ${ }^{[16,17]}$.

Closed reduction should be done as soon as possible. The chances of developing avascular necrosis of head of femur increases with the time the hip remains in dislocated position. Some authors suggests 4 hours from the time of injury to reduction is the allowed time for good result with less chances of AVN ${ }^{[18,19]}$. Reduction maneuvers should be less traumatic. Bigelow's method may be helpful in posterior dislocation and traction in the line of shaft with gentle rotations reduces the anterior dislocations in many cases ${ }^{[15]}$.

After reduction the hips should be immobilized for 3 weeks by giving skeletal or skin traction. Further non weight bearing period of 6-8 weeks with mobilization of the hip gives optimal results.

Few dislocations are associated with acetabular fractures. They may require definitive operative procedures after the hip is relocated. Anterior dislocation may compress the femoral vessels in some cases compromising the vascularity of the limb. Similarly sciatic nerve may be stretched in posterior dislocations causing neuropraxic injury.

\section{References}

1. Epstein HC. Traumatic dislocations of the hip. Clin Orthop 1973;92:116-142.

2. Clegg TE, Roberts CS, Greene JW, Prather BA. Hip dislocations-epidemiology, treatment, and outcomes. Injury 2010;41:329-34.

3. Civil ID, Tapsell PW. Simultaneous anterior and posterior bilateral traumatic dislocation of the hips: a case report. Aust NZJ Surg 1981;51:542-4.

4. Sinha SN. Simultaneous anterior and posterior dislocation of the hip joints. J Trauma 1985;25:269-70.

5. Hill RJ, Chmell S. Contralateral anterior/posterior traumatic hip dislocations. Orthpedics 1990;13:87-8.

6. Bansal VP, Mehta S. Bilateral hip dislocation: one anteriorly, one posteriorly. J Orthop Trauma 1991;5:86-8.

7. Nadkarni JB. Simultaneous anterior and posterior dislocation of hip. J Postgrad Med 1991;37:117-8, 118A.

8. Prem Sukla C, Shannon Cooke E, Charles Pollack V, James Kolbe C. Simultaneous asymmetric bilateral traumatic hip dislocation. Annals of Emergency Medicine 1993;22(11):1768-1771.

9. Lam F, Walczak J, Franklin A. Traumatic asymmetrical bilateral hip dislocation in an adult. Emerg Med J 2001;18(6):506-07.

10. Devgan A, Sharma S. Simultaneous post-traumatic 'criss cross' dislocation of hip joints-one anterior and other posterior. Injury 2004;35:1068-70.

11. Sraj SA, Lakkis S. Simultaneous anterior and posterior traumatic hip dislocation: a case report and review of literature. Injury Extra 2007;38:327-33.

12. Agarwal S, Singh GK, Jain UK, Jyoti G. Simultaneous anterior and posterior dislocation of the hip, a case report and review of literature. Archives of Orthopaedics and 
Trauma Surgery 120(3-4),236-238.

13. Papanikolaou A, Piotopoulos A, Darmanis S, Antoniou N. Bilateral Asymmetric hip dislocation, case report. European journal of Orthopaedic Surgery and Traumatology 10(4),269-271.

14. Raffaele Pascarella, Alessandra Maresssa, Michele Cappucio, Leonardo Reggiani M, Stefano Boriani. Asymmetric Bilateral traumatic fracture dislocation of the hip; A report of two cases. La Chirurgia degli organi di movimento 92(2),109-111.

15. Loupasis G, Morris ED. Asymmetric bilateral traumatic hip dislocation. Archives of Orthopaedics and Trauma Surgery 118(3), 179-180.

16. Letter to Editor: Is asymmetrical dislcotion really rare: Indian jeep drivers: Unusual mode. Soineet Agarwal. Emerg Med J published online, 2003.

17. Letter to Editor: Rare injury: unusual mode of trauma. Dr. Soneet Aggarwal, Prof. SS Sangwan, Dr. Vikas Yadav, Dr. Zile Singh. Emerg Med J published online, 2003.

18. Upadhayay SS, Moulton A, Srikrishnamurthy A. An analysis of the late effects of traumatic posterior dislocation of the hip without fractures. J Bone Joint Surg 1983;65B:150-157.

19. Hougaard K, Thomsen PR. Traumatic posterior dislocation of the hip-prognostic factors influencing the incidence of avascular necrosis of the femoral head. Arch Orthop Trauma Surg 1986;106:32-35. 